\title{
Interdicting International Drug Trafficking: a Network Approach for Coordinated and Targeted Interventions
}

\author{
Luca Giommoni ${ }^{1}$ (D) $\cdot$ Giulia Berlusconi ${ }^{2}$ (D) $\cdot$ Alberto Aziani $^{3}$ (D)
}

Accepted: 16 November 2020 / Published online: 8 February 2021

(C) The Author(s) 2021

\begin{abstract}
There is a relative dearth of literature on both the effects of cross-border interdictions and the impact of different types of interventions on international drug trafficking. This study identifies the main trafficking routes for cocaine and heroin, along with comparing the disruptive effects induced by targeted and noncoordinated interventions. It adopts a social network approach to identify the routes along which cocaine and heroin are trafficked, and then simulates the impact of different interdiction strategies on these two trafficking networks. The findings indicate that targeting countries based on their respective positions in the networks, as opposed to on the basis of the quantity of drugs exchanged, is more likely to disrupt drug flows. More specifically, concentrating law enforcement resources on countries with several incoming or outgoing trafficking connections, or those countries that mediate between producer, transit and consumer countries, would appear to be particularly effective in this regard. Interventions focused on specific trafficking routes are also likely to be effective if these routes have high edge betweenness centrality scores. This study contributes to extant understanding on the vulnerability of cocaine and heroin international trafficking networks, and, moreover, demonstrates that empirically-driven strategies are potentially more effective at interdicting international trafficking than non-strategic and noncoordinated interventions.
\end{abstract}

Keywords Policing drugs · Supply-side policies · Strategic interventions · Drug law enforcement · Cocaine trafficking $\cdot$ Heroin trafficking

Luca Giommoni

giommonil@cardiff.ac.uk

1 School of Social Sciences, Cardiff University, Glamorgan Building, King Edward VII Avenue, Cardiff CF10 3WT, UK

2 Department of Sociology, University of Surrey, Guildford, UK

3 Università Cattolica del Sacro Cuore and Transcrime, Milan, Italy 


\section{Introduction}

Drug law enforcement is the primary method for controlling illicit drugs across the globe (Collins 2014; Mejía and Restrepo 2016). Indeed, even countries with a notably lenient approach towards illicit drugs, such as the Netherlands, spend much more on enforcement than they do on prevention, treatment and harm reduction combined (Rigter 2006). In 2018, the US government allocated five billion USD to interdiction efforts - a $10 \%$ increase compared to 2017 - and one billion USD in an attempt to disrupt drug flows into the country (Executive Office of the President of the United States 2017). Reducing the supply of illicit drugs is also a key priority of the European Union (EU). The EU Drugs Strategy 2013-20 and Action Plan (2013-16) aim to 'contribute a measurable reduction of the availability of illicit drugs, through the disruption of illicit drug trafficking, the dismantling of organised crime groups [...], efficient use of the criminal justice system, effective intelligence-led law enforcement and increased intelligence sharing' (Council of the European Union 2012, 15).

Despite the popularity and the significant investment in drug law enforcement, several studies have questioned the outcomes of these interventions (e.g. Toth and Mitchell 2018), while others argue that a key reason for the lack of effectiveness of drug law enforcement is the dearth of research in this area (Caulkins 2017; Reuter 2017). This study builds on the scarce literature on international drug interdiction by simulating the potential impact of different strategies on international drug trafficking. More specifically, it takes advantage of publicly available data on cocaine and heroin flows to assess the disruptive effects produced by targeted interventions compared to non-coordinated ones.

The article is structured as follows. The next section discusses extant literature on both the efficiency and effectiveness of international drug interdictions, before delineating the aim of the current study. The proceeding sections present the methodology and the results of the analysis, respectively. The final section considers the implications of this study for law enforcement and policy. Technical details about the construction of the network are provided in the appendices.

\section{Drug Law Enforcement}

As Reuter notes, '[drug law enforcement] literature is slight in volume and not yet very insightful' (2017, 160). More specifically, interdiction-including interventions aimed at dismantling transnational drug trafficking - is an area in which empirical research is particularly scarce (Reuter 2014). Indeed, there are only a handful of studies that seek to inform counter-drug interdiction policy (Crane, Rivolo, and Comfort 1997; Magliocca et al. 2019; Reuter et al. 1988; Toth and Mitchell 2018). Even then, these studies are, firstly, primarily focused on the US context and cocaine, and secondly, invariably lack consistent evidence (Crane, Rivolo, and Comfort 1997; Reuter et al. 1988). Moreover, with a few exceptions (e.g. Magliocca et al. 2019; Toth and Mitchell 2018), most of these studies are dated.

Reuter et al. (1988) provided one of the first attempts to empirically investigate the impact of interdiction events. They simulated the impact of increased military resources on disrupting international drug trafficking flows, demonstrating that increasing counter-drug interdiction efforts was unlikely to have an impact on either the availability of cocaine or its consumption in the US. Indeed, the use of military assets has been found to have more of an impact on the levels of importation of cannabis from other countries (with the exception of Mexico) (Caulkins, Crawford, and Reuter 1993). 
Crane et al.'s (1997) study is perhaps one of the most cited and debated in this area. The authors examined data on cocaine prices and purity, concluding that interdiction efforts external to the US were a cost-effective strategy for increasing the price of cocaine, which, in turn, reduced cocaine usage. However, their study has been heavily criticised. For instance, a review by Manski et al. (2001) raised several concerns regarding the causal relationship between interdiction events and increases in the cocaine price, highlighting flaws in the method and data that were employed, and concluding that the study 'does not yield useful empirical findings on the cost-effectiveness of interdiction policies to reduce cocaine consumption' (Manski, Pepper, and Petrie 2001, 43).

Two more recent contributions focused on the US and cocaine, and suggested that the impact of counter-drug interdictions was likely to only be temporary, if not wholly counterproductive. Toth and Mitchell (2018) conducted interviews with high-level informants from the US Drug Enforcement Administration. They showed that interdiction events produce only temporary effects within international drug trafficking, and that traffickers adapt to drug law enforcement by displacing their activities tactically, geographically or temporarily. Magliocca et al. (2019) utilised a geographical agent-based model to predict traffickers' adaptation to interdiction initiatives. They found that traffickers adapt to interdictions by displacing to new areas, which, in turn, makes international drug trafficking more widespread and resilient in the aftermath of law enforcement interventions.

A growing area of research examines at micro-level how drug trafficking organisations respond to disruption (e.g. Morselli and Petit 2007; Bright et al. 2017; Wood 2017). Based on the analysis of criminal networks' structure and features, most studies in this line of research have focused on evaluating the immediate structural effects of interdiction strategies targeting key actors along the drug supply chain (e.g. Morselli and Petit 2007; Malm and Bichler 2011; Duxbury and Haynie 2018). By combining computational modelling and social network analysis, a few authors (Duxbury and Haynie 2019; Duijn, Kashirin, and Sloot 2014) have provided a further insight into how criminal groups can recover and adapt to network disruptions. For instance, Duijn et al. (2014) discovered that criminal networks may even become more resilient after targeted attacks. Although these studies offer valuable insights for law enforcement authorities, they suffer from two main limitations for counter-drug interdiction policies: (1) with the sole exception of Morselli and Petit (2007), they focus on domestic rather than international drug trafficking organisations; (2) while pointing out the effect of an intervention on a single group, they do not inform us on the overall impact of the intervention on trafficking flows.

Both Reuter $(2014,2017)$ and Caulkins (2017) identified several reasons for the lack of a thriving drug law enforcement research agenda. First, there is a lack of funding in this specific area of drug policy. This is because, while drug law enforcement absorbs most of the spending on drug control, prevention and treatment receive the lion's share of drug research funding (Caulkins 2017; Reuter 2017). This contributes to the poor quality of data and estimates on both interdiction intensity and drug trafficking routes, which makes it even more challenging to produce sound policy analysis (Reuter 2014).

Second, drug law enforcement is a broad term which is used to designate a range of interventions that lie on a continuum from eradication in source countries to arresting drug users (Babor et al. 2010; Collins 2014), and whose assessment should therefore consider different outcomes, locations, and research designs. For example, a successful intervention for targeting cocaine trafficking may not be successful for cannabis, while what works for coastal countries, such as Australia, might not work for land-locked countries, such as Austria. To 
further complicate matters, drug law enforcement can also have different goals. While reducing drug use is often the primary objective, law enforcement agencies may also seek to reduce drug-related violence or weaken criminal organisations' territorial control (Reuter 2017).

Caulkins (2017) pinpoints academics' antagonism towards drug law enforcement as a further reason for the limited research on the topic. Given that they are often ideologically opposed to drug law enforcement agencies, researchers thus aim to discredit their work by drawing attention to their poor performance and various side-effects. Perhaps it is not a surprise, then, that enforcement agencies and governments are not inclined to fund academic research on drug law enforcement.

The scarcity of research in this area goes some way to explain why both so little has changed over the years in terms of how Western drug enforcement agencies respond to international drug trafficking, and why counter-drug interdictions have proven to be so ineffective (Balbirnie et al. 2016; Caulkins and Reuter 2016; Collins 2014). A recent evaluative study on the implementation and impact of the EU Drugs Strategy and related Action Plan for the period 2013-2016 found that, although the latter has been implemented and considerable progress has undoubtedly been made, there remains no evidence that the current supply-side strategies have reduced the availability of illicit drugs in the EU (Balbirnie et al. 2016). In the US context, Marshall (1988) stressed the need for empirically-driven drug law enforcement strategies more than 30 years ago, warning that 'we are flying blind in the war on drugs' (Marshall 1988, 1605), and that greater resources should be invested in drug policy analysis and strategy. Similarly, the European Council emphasised the need for more empirical work in this important policy area, while the EU Drugs Strategy 2013-20 has called for more research-driven action, arguing that drug law enforcement, among other things, should be evidence-based and scientifically sound. Despite this, there remains a dearth of research on this important security, policy, and strategic issue.

\section{The Current Study}

This study contributes to extant drug law enforcement literature by identifying which interdiction strategies are likely to impact on the international trafficking of cocaine and heroin. Effective drug interdiction requires a high-level of coordination and information sharing between the various law enforcement agencies involved in such interventions. This is especially relevant in the EU context, where ineffective interdiction strategies in a member state can have knock-on effects on other states due to the free movement of goods, persons, and capital across the region. In this respect, a shipment of cocaine entering Spain, or heroin crossing the Greek border, can have implications for the entire EU, while, conversely, effective interdictions in key countries can have impacts that extend to all member states.

Nonetheless, simply increasing the available resources for, and the intensity of, border controls does not in itself ensure higher interdiction rates (Collins 2014; Kleiman 2011). Moreover, drug law enforcement agencies should also avoid evenly allocating resources across potential targets, which has proven to have limited effects in multiple fields. Instead, they should focus their attention on countermeasures whose efficacy and efficiency has been proven by solid evidence (Felbab-Brown 2014; Kleiman 1999). The current study shows that targeted interventions, whose design is grounded in empirical data on drug trafficking between countries, have greater potential to disrupt trafficking flows than non-coordinated interventions. 
This study focuses on the two primary targets of international counter-drug interventions: cocaine and heroin. These two drugs are produced in specific geographical areas - cocaine in the Andean region, and heroin in Southwest Asia - and typically need to cross multiple borders before reaching consumer markets (Caulkins 2015). This makes interdiction a key drug supply reduction strategy. Interdiction is of less relevance in the enforcement of the supply of other drugs such as cannabis and synthetic drugs, which are often produced domestically and, thus, are close to consumer markets (EMCDDA 2019; UNODC 2019a).

This paper contributes to extant drug law enforcement literature in three ways: (1) it provides the first simulation of the impact of different interdiction strategies on cocaine and heroin trafficking outside of the US; (2) it provides a tool through which to inform drug law enforcement agencies' decisions and enhance the efficiency of their interventions; (3) it identifies key countries that, given their respective positions in the international drug trafficking network, should mobilise and lead counter-drug interdictions.

\section{Methodology}

\section{Cocaine and Heroin Trafficking Networks}

This study conceives of cocaine and heroin trafficking as two weighted and directed networks, in which nodes represent countries and edges identify drug trafficking between any two countries. We used the methodology developed by the UNODC (2015b) to estimate the presence and weight of the edges in the cocaine and heroin networks. This methodology is based on five main steps (Fig. 1): (1) identification of connections between any two countries; (2) estimation of the relative weight of each connection with respect to each country's other incoming flows; (3) estimation of the quantity of drug consumed and seized in each country;
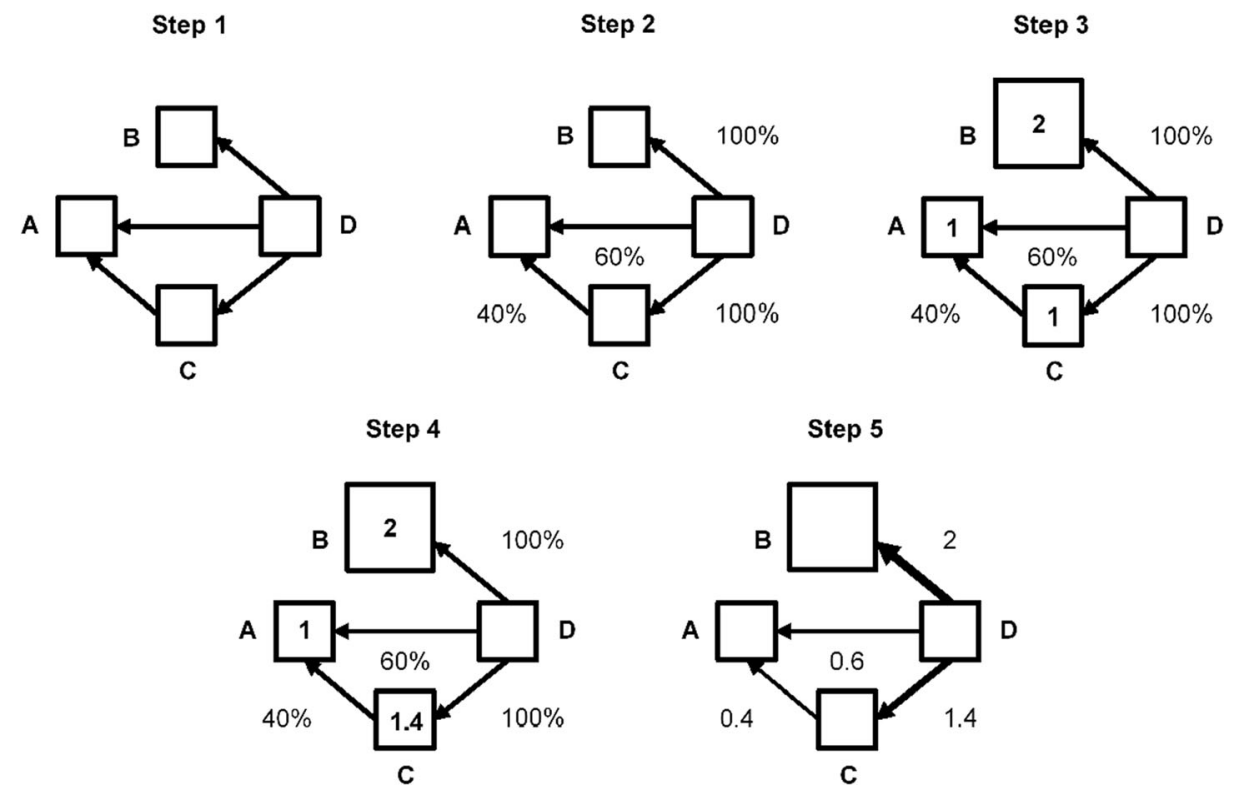

Fig. 1 Steps taken to construct the cocaine and heroin trafficking networks 
(4) estimation of the total quantity of drug imported by each country; (5) estimation of the quantity of drug exchanged between any two countries. We produced year-by-year estimates of both cocaine and heroin trafficking flows (2011-2016) and calculated their mean over the entire period.

Step 1 identified connections - i.e. drug trafficking flows - between any two countries. To do this, we drew on the UNODC Individual Drug Seizure (IDS) dataset for the period 2011-2016. Seizure data often includes information on the quantity of drugs intercepted by law enforcement agencies, the country where the seizure occurred, and the origin, transit, and-occasionally-destination country. For the years 2011-2016, the IDS dataset contains 13,021 records of seizures of coca derivatives and 8052 records of seizures of opium and its derivatives providing indications of 19,155 and 11,652 connections in the cocaine and heroin trafficking networks, respectively. The resulting cocaine network comprised 147 countries and 817 edges while the heroin network included 137 countries and 437 edges.

Step 2 involved estimating the relative weight (\%) of each connection with respect to each country's other incoming flows. We used information on the quantity of drug intercepted along the identified connections to obtain these estimates. We adjusted each seizure case for its estimated purity, which was calculated as the average purity of the drug at wholesale level in the importing and exporting countries. ${ }^{1}$ Finally, we estimated the relevance of each edge with respect to the total seizures performed by importing countries:

$$
F_{d, t, j \leftarrow k}=S_{d, t, j \leftarrow k} / \sum_{k=1}^{K} S_{d, t, j \leftarrow k}
$$

where $S_{d t}$ is the quantity of drug $d$ seized in year $t, j$ is the importing country, and $k$ is the exporting country. Figure 1 shows an example where $60 \%$ of the drugs seized by country A were smuggled from country D, while $40 \%$ was coming from country C. See Appendix 2 for further details.

A first limitation of this approach is that out of scale seizures may distort the estimates as particularly large seizures may reflect either an increase in shipments or luckier law enforcement operations (MacCoun and Reuter 2001; Kilmer and Hoorens 2010; Aziani 2018). ${ }^{2}$ This is rarely the case for land and air routes because loads tend to be limited in scale; it may however be more likely in the case of sea connections, whose shipments are possibly larger. We used three-year moving averages to mitigate possible distortions driven by bulky seizures or limited data reporting in any given year. ${ }^{3}$

Step 3 comprised estimating the total quantity of drug consumed and seized in each country, i.e. the quantity of drug that a country needs to import in order to satisfy its

\footnotetext{
${ }^{1}$ Not accounting for purity levels might inflate the relevance of flows occurring between downstream countries, where drug might be more cut (Paoli, Greenfield, and Reuter 2009). Since the UNODC (2019a) does not provide data on purities for all countries in the two networks, regional data on purity was used whenever national data was not available, and macro-regional data was used in a few cases where regional data was also missing.

${ }^{2}$ See Appendix 1 for further details on the distribution of cocaine and heroin seizure cases across countries. Summary statistics on seizures cases by importing country are available on the authors' Open Science Framework project profile at https://osf.io/cbdqa/?view_only=ef82eec308b0403e99a753ace4cac690.

${ }^{3}$ In any given year, the estimate of the seizures along each route $\left(S_{m a, t}\right)$ is a function of the seizures performed along the route in the given year $\left(S_{t}\right)$ as well as the seizures performed in the previous $\left(S_{t-1}\right)$ and following year $\left(S_{t+1}\right)$. Seizures for the previous and following year enter in the calculus with a weight, which is half the weight of the year under consideration: $S_{m a, t}=S_{t}+\left(S_{t-1} / 2\right) \frac{+\left(S_{t+1} / 2\right)}{2}$.
} 
internal demand. To estimate the quantity of drug consumed in each country, we used a combination of demand- and supply-based approaches. First, we estimated the total quantities of cocaine and heroin available for consumption, starting from the UNODC (2019b) estimates of the global production of the two drugs. Second, we divided these quantities by the global estimates of the number of users of the two substances, thus obtaining estimates of the annual consumption per user. Third, for each country, we multiplied the estimated number of users by purity-adjusted estimated quantities of cocaine and heroin consumed by each user (Kilmer et al. 2013, 2011; Legleye, Lakhdar, and Spilka 2008; Wilkins, Bhatta, and Casswell 2002). Finally, we adjusted seizures for purity to make them comparable across countries before adding them to the total quantity of cocaine and heroin consumed (Paoli, Greenfield, and Reuter 2009). See Appendix 3 for further details.

Step 4 estimated the total quantity of drug imported by each country. For non-producing countries, this was equivalent to the sum of the quantity of drug consumed and seized (Step 3) and the quantity of drug imported and then exported to other countries. In the toy model proposed in Fig. 1, country $\mathrm{C}$ imported one ton of drug to meet its internal demand and an additional $40 \%$ to export to country A, for a total of 1.4 tons.

Step 5 involved estimating the quantity of drug exchanged by any two countries. As Fig. 1 shows, country B required a total of two tons to satisfy its internal demand. Given that $100 \%$ of the seized drugs came from country D, we assumed that country B imported the two tons from country D. $60 \%$ of country A's imports came from country D, while the remaining $40 \%$ came from country $\mathrm{C}$, which led to an estimate of 0.6 tons having been exchanged between country $\mathrm{D}$ and country A, and 0.4 tons between country C and country A. See Appendix 4 for further details on the algebra behind step 5. Finally, we calculated the average of all annual estimates (2011-2016) to alleviate possible distortions due to exceptional events and episodic issues in data reporting.

\section{Producing, Transit, and Consumer Countries}

We classified the countries in the cocaine and heroin networks into three groups-'producer', 'transit', and 'consumer' countries - according to the role that they play in international drug trafficking. These labels identify the main role of countries, as only a few are exclusively consumers (i.e. they do not export drugs), while none are exclusively a transit country (i.e. they do not have any internal consumption). This classification will be used subsequently to identify the most effective interception strategies.

'Producer' countries were identified based on data on coca and poppy cultivation published by the UNODC (2019a). The main cocaine producers were Bolivia, Colombia, Ecuador, and Peru, while the main heroin producers included Afghanistan, Colombia, Laos, and Myanmar. We used information on drug imports and exports to classify countries as 'transit' or 'consumer'. The natural logarithm of the ratio between total exports and consumption in each country was taken as a measure of countries' main role in transnational drug trafficking. That is to say, the higher the ratio, the more pronounced the transiting role played by a country; the lower the ratio, the more a country is a destination market. We then classified the countries by partitioning them into two non-overlapping clusters through the use of a k-medians method, as any threshold to discriminate between 'transit and 'consumer' countries would introduce an element of arbitrariness in the absence of further information. A 
list of the countries that make up the cocaine and heroin networks and their cluster is available on the authors' Open Science Framework project profile, while Table 1 provides a summary of the clusters. ${ }^{4}$

\section{Network Statistics and Simulations}

The first part of our analysis focused on providing descriptive statistics of the two networks. ${ }^{5}$ We quantified network parameters by using social network analysis measures. More specifically, we used density (i.e. the proportion of edges in the network) and mean degree (i.e. the average number of edges for the countries in the network) to assess the degree of network cohesion (Wasserman and Faust 1994). We also used centralisation measures to assess whether the networks were characterised by the presence of a few trafficking hubs, or whether most of the countries had similar levels of involvement in trafficking activities (Giommoni, Aziani, and Berlusconi 2017).

We also calculated statistics for every country within the two networks, namely, degree centrality, betweenness centrality, and Gould and Fernandez's (1989) brokerage measures. Degree centrality measures the number of countries that a country imports drugs from (indegree) or exports drugs to (out-degree). Betweenness centrality measures the number of times that a country is located along the shortest path between any other two countries in the network (Wasserman and Faust 1994).

Gould and Fernandez's (1989) brokerage measures afford the identification of the different brokerage roles that countries perform in the cocaine and heroin networks, respectively. They are based on the idea that 'flows within groups should in general be distinguished from flows between groups' $(1989,91)$. While betweenness centrality is expedient for identifying the countries that are located along drug trafficking routes, Gould and Fernandez's brokerage roles are valuable in terms of identifying the countries that liaise between 'producer', 'transit', and 'consumer' countries.

Gould and Fernandez (1989) identified five brokerage roles (Fig. 2):

- Coordinators mediate between two countries in the same cluster, such as in the case of a 'transit' country which lies along a drug trafficking route between two countries that are also primarily involved in transit activities (Fig. 2A).

- Itinerants mediate between two countries from the same cluster, while belonging to a different cluster (Fig. 2B). A 'transit' country connecting two 'producer' countries is an example of this type of mediating role.

- Representatives and gatekeepers mediate between two countries from different clusters. However, representatives share the same cluster as the country exporting drugs, whereas gatekeepers share the same cluster as the country importing drugs (Fig. $2 \mathrm{C}$ and D, respectively).

- Liaisons mediate between two countries in two different clusters, while, simultaneously, belonging to a third cluster. This relates to the case of a 'transit' country that lies on a drug trafficking route between a 'producer' and 'consumer' country.

\footnotetext{
${ }^{4}$ https://osf.io/cbdqa/?view only=ef82eec308b0403e99a753ace4cac690.

${ }^{5}$ The analyses were performed using the 'network' and 'sna' packages (Butts 2015, 2016) for R (R Core Team 2019).
} 
Table 1 Countries' clusters

\begin{tabular}{lll}
\hline Role & Cocaine & Heroin \\
\hline Producer & $4(3 \%)$ & $4(3 \%)$ \\
Transit & $32(22 \%)$ & $34(25 \%)$ \\
Consumer & $111(75 \%)$ & $99(72 \%)$ \\
\hline
\end{tabular}

The inclusion of Gould and Fernandez's brokerage roles allowed us to consider not only the position of countries within the entire network - as indicated by betweenness centrality - but also their capacity to connect different clusters. This is valuable information for developing targeted interdiction strategies, given the different clusters that countries belong to in the international trafficking of cocaine and heroin (i.e. producer, transit, and consumer). For instance, intervening in a transit country that plays a coordinating role may produce a very different impact on drug trafficking flows than intervening in the same country if it acts as a liaison between 'producer' and 'consumer' countries, even if the betweenness centrality score for that country is the same.

The second part of the analysis tested the impact of different interdiction strategies on the level of connectivity within the networks, and on countries' closeness to all other countries in the network, in order to identify those strategies that were more likely to have a disruptive effect on cocaine and heroin flows between countries. Specifically, we measured network connectivity by producing the reachability matrix-i.e. the matrix that identifies whether any two nodes are connected by one or more directed paths - and calculating its density to obtain the fraction of all dyads (i.e. pairs of countries) that are connected through a directed path (Wasserman and Faust 1994). We measured countries' closeness by calculating the average closeness centrality score for all countries in the network using Opsahl et al.'s (2010) approach, which can be used for fully connected networks and networks with disconnected components alike. We simulated two types of interdiction strategies.

The first strategy focused on countries. It was based on the removal of nodes (i.e. countries) from the networks, and tested the disruptive effect of concentrating interdiction resources within specific countries. Vertices were removed: (1) randomly; based on (2) unweighted and (3) weighted in-degree centrality scores; based on (4) unweighted and (5) weighted out-degree centrality scores; (6) based on betweenness centrality scores; and (7) based on the five brokerage roles identified by Gould and Fernandez (1989). With respect to both random removal and those cases in which more than one country had the same score, we simulated node removal 100 times, and reported the average connectivity and closeness scores for the 100 replications.

A. Coordinator
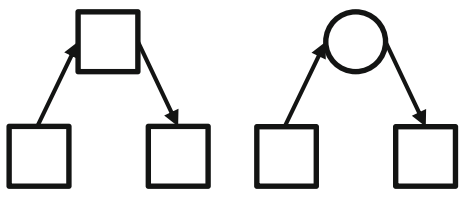

Legend

$\nabla$ 'Producer' country
B. Itinerant

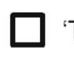

C. Representative

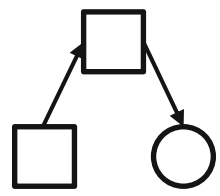

'Transit' country
D. Gatekeeper
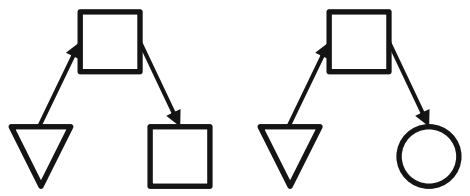

'Consumer' country

Fig. 2 Examples of Gould and Fernandez brokerage roles in the cocaine and heroin networks 
The second strategy focused on drug routes. It was based on the removal of edges from the networks, and tested the effect of concentrating interdiction resources on specific trafficking routes between countries. Edges were removed: (1) randomly; (2) based on their weight, i.e. the estimated quantity of drugs exchanged between any two countries; (3) based on their edge betweenness, i.e. the number of times an edge occurred on the shortest path between any two countries (Freeman 1979); (4) based on whether they connected two countries in the same cluster (e.g. two 'transit' countries); (5) and based on whether they connected two countries in different clusters (e.g. a 'transit' and a 'consumer' country). Similar to above, for the purposes of both random removal and those cases in which more than one edge had the same score or fell within the same category, we simulated edge removal 100 times, and reported the average connectivity and closeness scores for the 100 replications.

Supply-side reduction policies in producing countries have thus far been proven to have only a marginal impact on the availability of drugs, if not actually being wholly detrimental (Angrist and Kugler 2008; Collins 2014; Mejía and Restrepo 2016; Veillette 2005). In consideration of previous literature which has already addressed the limitations of supply-side interventions in producer countries, we excluded these countries from node removal, and instead solely focused on 'transit' and 'consumer' countries. It should also be acknowledged that there is a cost factor associated with removing nodes or edges that must be considered in the development of drug interdictions strategies. For instance, although enforcing the border between Mexico and the United States is likely to be more disruptive than interdiction strategies targeting the connection between Belize and Mexico, the former also involves higher costs. This paper focuses exclusively on the benefits that targeted interventions may produce but overlooks their costs. This kind of cost-benefit analysis is outside the scope of this paper but should be further investigated by future research.

Finally, it is worth emphasising here that the aim of our simulations is not to literally remove a country or a trafficking route, as sealing borders and impeding illicit drugs from penetrating a country has been found to not be practically achievable. Rather, our analysis aims to inform drug law enforcement by showing where interdiction efforts are more likely to have the most disruptive effects on the entire drug trafficking network. At a historical juncture characterised by reduced public expenditure, our analysis can both inform how scarce resources are allocated and increase the effectiveness of drug law enforcement.

\section{Limitations}

Our approach is not without its drawbacks. Specifically, seizures might not be fully representative of actual drug flows. First, it is reasonable to expect a degree of heterogeneity in the effectiveness of different agencies' enforcement activities, as drug policies vary across countries, and air and sea routes are easier to enforce than land routes (Reuter, 2014). Therefore, seizure data are likely to over-estimate the relevance of drug trafficking within more aggressive countries, and along sea and air routes.

Second, while seizures account for a large share of inflows in several countries, they are limited and only account for a small fraction of total inflows in other countries - see Appendix 5 for the share of cocaine and heroin seized, consumed and exported by each country. Moreover, some countries do not report information on drug seizures to the UNODC every year, while others report only certain cases or avoid sharing any information at all (UNODC 2019b). Certain trafficking connections thus emerged from limited evidence. Finally, as 
already discussed, particularly large seizures might introduce an upward bias in the estimate of the relative relevance of a specific connection between two countries.

The combined use of information from multiple countries in multiple years helps mitigate the consequences stemming from countries' differences in counter-drug efforts and seizure reporting, changes in countries' border control activities, and exceptionally large seizures that might skew our estimates (Berlusconi, Aziani, and Giommoni 2017). Moreover, while working on the 1998-2014 UNODC cocaine IDS, Aziani (2018) noted that importing countries provide the vast majority of information actually usable to build a network. Since the relevance of each connection is estimated with respect to the importing country-i.e. through a comparison of incoming flows - this fact further reduces the biases due to different law enforcement and reporting systems, as these differences are likely to be more severe between countries than within countries. Nonetheless, the extent to which seizures represent actual flows or enforcement capacity remains unknown (MacCoun and Reuter 2001; Kilmer and Hoorens 2010); therefore, the resulting networks are an approximation of the drug trafficking activities taking place worldwide rather than their faithful reconstruction.

There are further uncertainties pertaining to our assumptions about users and their consumption, along with drug purity. The heterogeneity of data available across countries forces us to rely, from time to time, on linear interpolations and eventually on regional values. The lack of estimates is particularly severe with respect to quantities of drug consumed by the average user, which has thus been estimated starting from drug production data (see Appendix 3 for details). A series of inconsistent reports by government agencies and international organizations, together with the impossibility to state the exact time lag between drug production and consumption, led several authors to be sceptical about supply-side estimations (Reuter and Greenfield 2001; Kilmer, Reuter, and Giommoni 2015). While we do agree with this position, in the context of the current study, the limits of this strategy primarily concern the lack of adjustments for national consumption values per user and eventually a bias in the relative weight of consumption and seizures. Uncertainties about the time lag between production and consumption are instead likely to affect only marginally our analyses because we combine estimates referring to multiple years, and because the analysis of law enforcement interventions is not performed on a dynamic network.

Despite these aforesaid limitations, the approach adopted in this study has been extensively applied in other studies because of its unique capacity to produce new information on the existence of trafficking activities from available data (Dugato and Aziani 2020). Paoli, Greenfield, and Reuter (2009) were the first to conceive of international drug trafficking as a series of trading relations across countries. Boivin (2013, 2014a, 2014b) utilised information from seizures to study the network structure of international drug trafficking, while Chandra et al. $(2011,2014,2015)$ used a similar approach to analyse drug trafficking flows across countries, albeit they constructed their networks with price-based data rather than seizure data. The UNODC (2015b) developed a model to estimate heroin trafficking flows along the Balkan route, with the same methodology subsequently being used in academic articles on cocaine and heroin trafficking (Aziani, Berlusconi, and Giommoni 2019; Berlusconi, Aziani, and Giommoni 2017; Giommoni, Aziani, and Berlusconi 2017). Hence, this is an established method through which to estimate drug trafficking across countries. 
Table 2 Network statistics

\begin{tabular}{llr}
\hline Statistics & Cocaine & Heroin \\
\hline Network size & 147 & 137 \\
Network edge count & 817 & 437 \\
Density & 0.04 & 0.02 \\
Mean degree & 11.12 & 6.38 \\
In-degree centralisation & 0.35 & 0.19 \\
Out-degree centralisation & 0.46 & 0.45 \\
Betweenness centralisation & 0.26 & 0.28 \\
\hline
\end{tabular}

\section{Results}

\section{The Structure of Cocaine and Heroin Trafficking Networks}

The cocaine and heroin trafficking networks comprise 147 and 137 nodes, respectively (Table 2). While both networks show a low density, countries involved in heroin trafficking have, on average, fewer direct connections than those within the cocaine network, thus suggesting that heroin tends to be concentrated along fewer routes than cocaine, which is trafficked along several alternative routes. The production of heroin takes place in three distinct areas - Afghanistan, South-East Asia, and Latin America — and with respect to heroin trafficking, specific source and trafficking countries serve specific consumer countries (Paoli, Greenfield, and Reuter 2009; Meylakhs 2017). Conversely, cocaine is produced exclusively in few Andean countries; from there cocaine reaches its final markets located in all continents. These differences between the two illicit markets might explain the lower number of direct connections in the heroin trafficking network in comparison to the cocaine network.

Centralisation measures indicate that incoming and outcoming edges are not equally distributed in the two networks. This is particularly true for the latter, suggesting that most countries export to only one or a few other countries, while a small number of exporters have several outgoing edges. This is reinforced by Fig. 3, which shows some differences in the distribution of edges between the countries in the two networks, and with respect to the analysis of countries' centrality scores. Centrality scores for the countries in the two networks are available on the authors' Open Science Framework project profile. ${ }^{6}$

The countries with the highest centrality scores in the cocaine network are Spain (121), Ecuador (72), Venezuela (72), Italy (70) and Portugal (67). Almost all the connections for Ecuador and Venezuela are outgoing, thus indicating that these countries are mainly exporters, while Spain has a similar number of incoming and outgoing edges. Pakistan (67), Spain (43), Bulgaria (31), Italy (30) and Germany (26) are the countries with the highest centrality scores within the heroin network. While for Pakistan most of these connections are outgoing, Italy primarily has incoming edges, which suggests that the country imports heroin from several exporters. It is important to stress here that a high centrality score in and of itself does not necessarily indicate that a country exchanges large quantities of drugs, while, conversely, a low centrality score does not necessarily indicate a low-volume of imports or exports. Indeed, a single connection may be enough to either satisfy a country's demand for drugs, or exchange large quantities of drugs. The analysis of betweenness centrality scores suggests that Spain, Portugal, Germany, Italy and France are the countries that most regularly are located along the

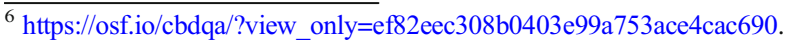



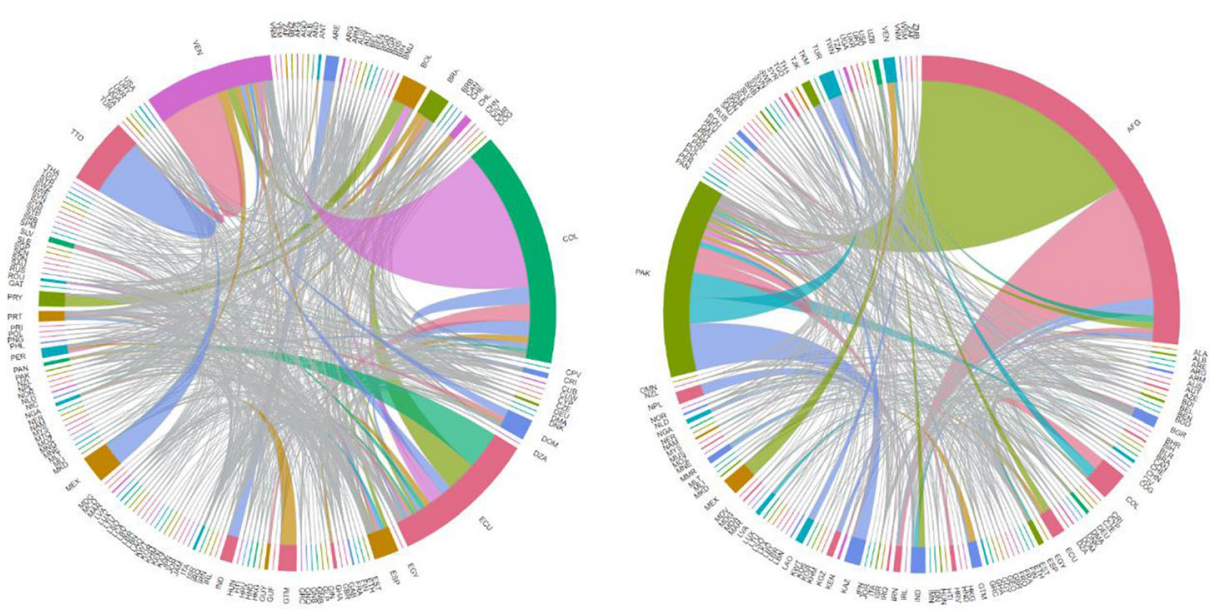

Fig. 3 The cocaine (left) and heroin (right) networks. The chord diagrams for cocaine and heroin flows were created using the 'chorddiag' package (Flor, 2019) for R (R Core Team, 2019). Interactive versions of the diagrams are available at http://rpubs.com/gberlu/cocaineflows and http://rpubs.com/gberlu/heroinflows, respectively

shortest path between any other two countries in the cocaine network, thus indicating that these countries are important trafficking hubs. Spain, who has the highest betweenness centrality score, also plays a key role in the heroin trafficking network, while Pakistan, the United Kingdom, Bulgaria and Russia are also located along several trafficking routes. The high betweenness centrality score for Spain in the cocaine network has a partial explanation in the fact that Spain is a fundamental point of entry of shipments coming from Latin America. The increase in production of heroin in Latin America, which has been taking place in the last years, might give Spain a more central role in the heroin network, too.

Gould and Fernandez's brokerage measures offer a more nuanced analysis of countries' brokerage roles. While some countries have relatively high scores for all brokerage measures (e.g. Spain in the cocaine network), many others have high scores for only one or two measures, which suggests that their brokerage role is limited to facilitating exchanges between or within clusters. For instance, in the cocaine network, Italy is the main coordinator, insofar that it is a 'consumer' country that mediates between several pairs of 'consumer' countries. Portugal is second only to Spain in its liaison and representative role, which suggests that it either regularly liaises between producer and consumer countries, or mediates between another country that is primarily involved in trafficking activities and a country from a different cluster. The brokerage measures also highlight the role of Venezuela - mainly in a liaison role - and Nigeria - mainly in terms of a gatekeeper - in facilitating the exchange of cocaine between countries. Nigeria also ranks as the third highest coordinator within the heroin network, while the Netherlands, a well-known redistribution centre for heroin in Europe, is one of the leading countries in terms of playing an itinerant and representative role.

\section{Simulation of Drug Interdiction Strategies}

Figure 4 shows the impact of different interdiction strategies on the level of connectivity within the cocaine network. The initial network connectivity was 0.52 , i.e. $52 \%$ of pairs of countries were connected through a directed path. The network connectivity decreased as we removed 

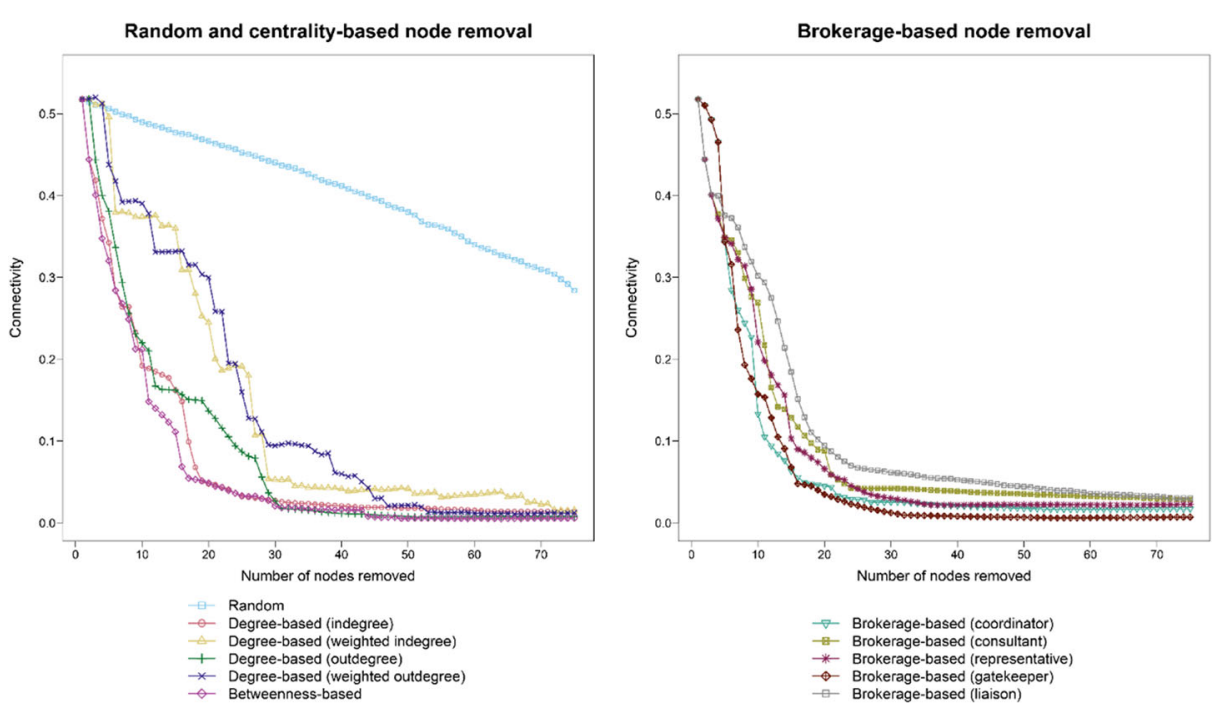

Fig. 4 Impact of different node removal strategies on the level of connectivity of the cocaine network

vertices randomly, as well as based on countries' degree, betweenness, and brokerage scores. Of the eleven node removal strategies tested, random removal proved to be the least effective, while targeted interventions were found to have a differential impact depending on the number of nodes that were removed. After the removal of five nodes, several strategies - based on unweighted in-degree, betweenness, and coordinator roles - appeared to have a similar impact. When ten nodes were removed, targeting coordinators, i.e. those that mediate between two countries in the same cluster, appeared to be the most effective strategy, followed by targeting gatekeepers and nodes with the highest betweenness scores. Targeting countries that operate in a gatekeeper role became especially valuable after the removal of approximately twenty nodes, and remained one of the most disruptive strategies when half of the nodes were removed together with countries with the highest betweenness scores. Targeting countries based on their position in the network, rather than, say, based on the quantity of cocaine exchanged, would thus appear to be an effective interdiction strategy. Indeed, targeting countries that import or export large quantities of cocaine did not appear to be as disruptive as targeting countries that played a key role in the trafficking network, and whose removal had a considerable impact on the overall network structure.

The simulation of interdiction strategies that targeted countries involved in heroin trafficking produced similar results (Fig. 5). The initial network connectivity was 0.56 , i.e. $56 \%$ of pairs of countries were connected through a directed path. Random strategies were found to be the least efficient, while targeting countries with the highest betweenness scores proved to be particularly effective after the removal of five nodes and, allied with the targeting of coordinators and gatekeepers, ten nodes. As the number of nodes removed increased, targeting gatekeepers remained a valuable strategy, albeit interdiction strategies based on in-degree and out-degree centrality also became relevant.

Figure 6 reports the impact of edge removal on the connectivity of the cocaine and heroin networks. Overall, node removal had a greater impact on connectivity than edge removal, as the removal of a node was likely to disrupt several drug routes at once. The simulation demonstrated that the removal of up to ten edges had little impact on the connectivity of the 

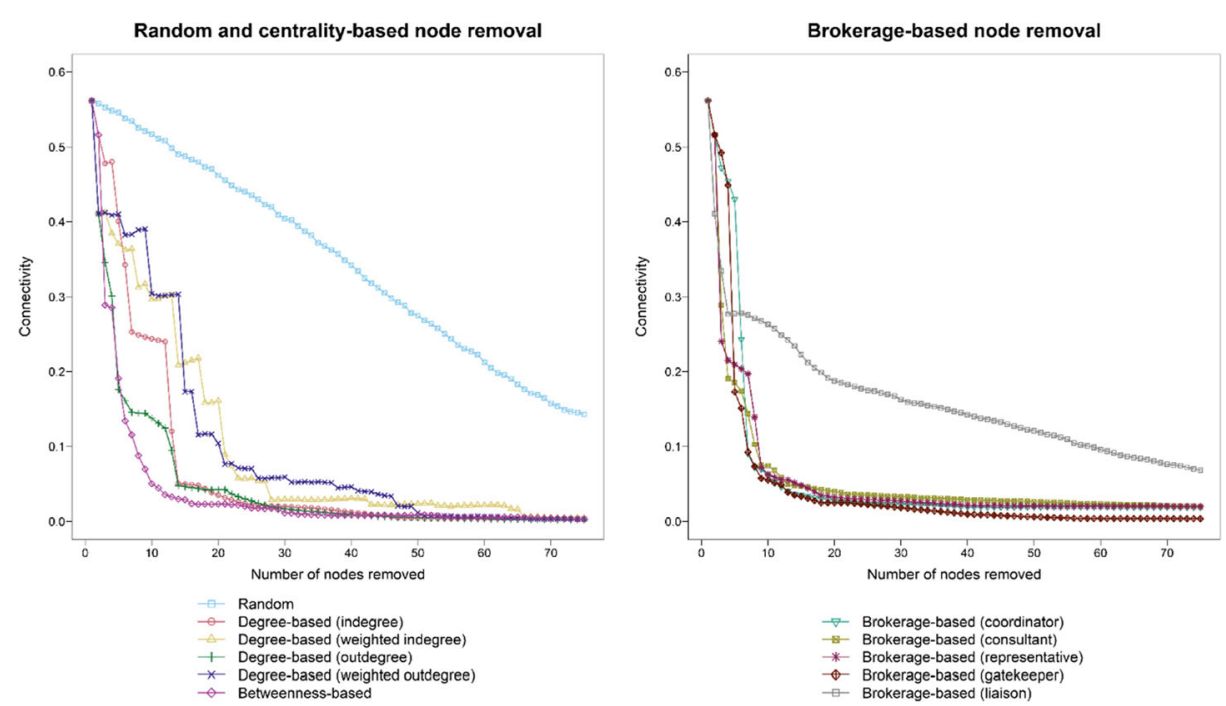

Fig. 5 Impact of different node removal strategies on the level of connectivity of the heroin network

network, while there was little difference between random and targeted interventions. However, the removal of edges with high betweenness scores slightly outperformed the other strategies, and became the most effective approach as the number of edges removed from the network increased. Targeting edges that connected countries in different clusters was among the most effective approaches through which to disrupt the heroin network, whereas removing edges that connected countries in the same cluster was a particularly effective strategy for reducing the supply of cocaine. An interesting feature of interdiction strategies that target specific drug routes rather than countries is that targeted interventions are not necessarily more
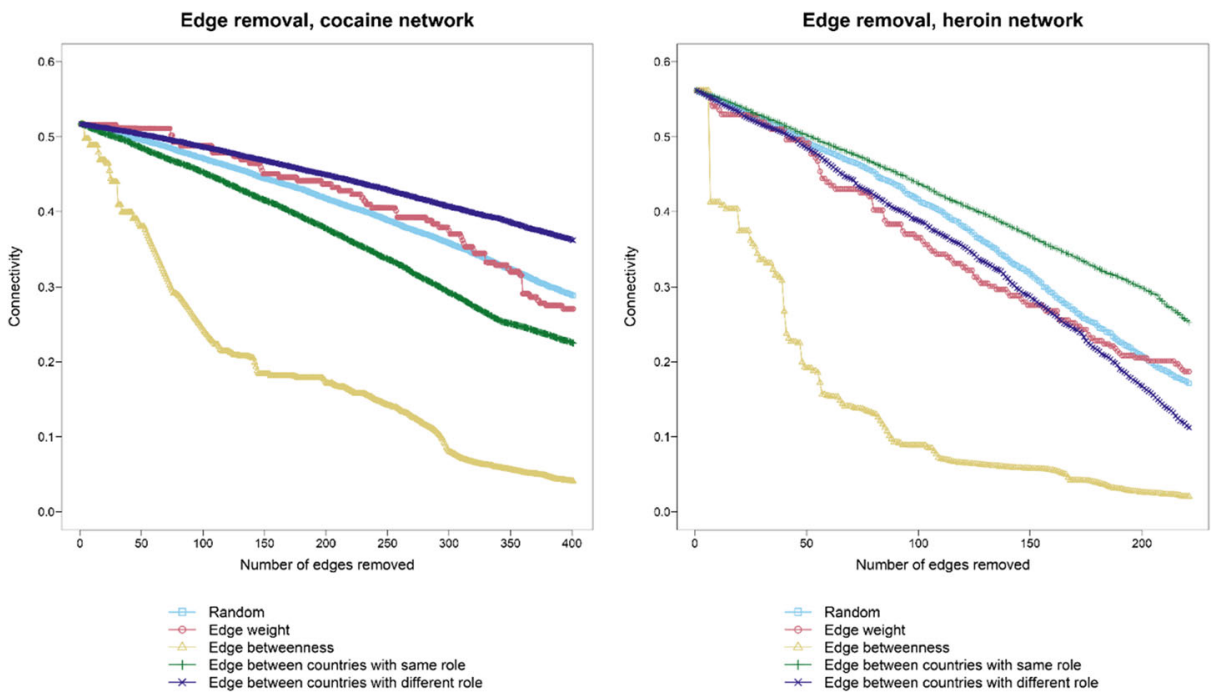

Fig. 6 Impact of different edge removal strategies on the level of connectivity of the cocaine (left) and heroin (right) networks 
efficient than random interventions, particularly when interdiction focuses on a limited number of edges. Indeed, random interventions can be more disruptive than interventions that target edges based on their weight, i.e. the estimated quantity of drugs exchanged between any two countries.

Figures 7, 8, and 9 report the impact of node and edge removal on countries' mean closeness in the cocaine and heroin networks. The results corroborate those already observed for network connectivity. Among the node removal strategies tested, random removal was always the least effective, while targeted interventions were found to have a differential impact according to the number of nodes that were removed. Here as well targeting countries based on the role they played in the network was more disruptive than removing countries based on the quantity of drug exported or imported.

The results of the edge removal show some similarities but also an important difference. Edge removal had a smaller impact on closeness than node removal, as already observed for connectivity. The removal of edges based on their betweenness scores had a greater impact than the other strategies, and was found to be the most effective approach. Perhaps more importantly, the results show that the removal of edges based on the quantity of drug exchanged (i.e. the edge weight) is not necessarily an effective strategy at increasing the distance between countries in the two networks, i.e. increasing the number of steps needed to move the drug along the transnational supply chain.

\section{Discussion}

The density and mean degree of the two networks suggest that heroin tends to be concentrated along fewer routes than cocaine, although in both cases traffickers exploit only a limited number of selected routes, which is in accordance with the findings of previous studies (Boivin 2014b; Chandra and Joba 2015; Giommoni, Aziani, and Berlusconi 2017). This draws attention to the non-random nature of drug trafficking routes. Rather, social, economic, and
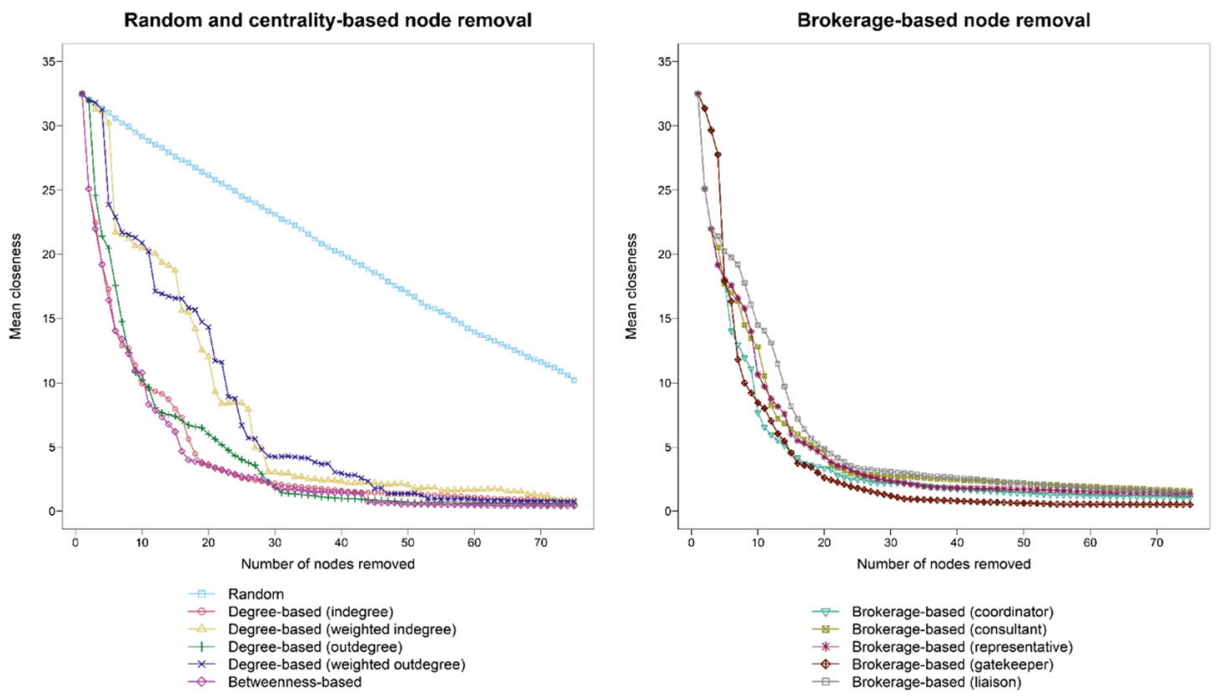

Fig. 7 Impact of different node removal strategies on the mean closeness of countries in the cocaine network 

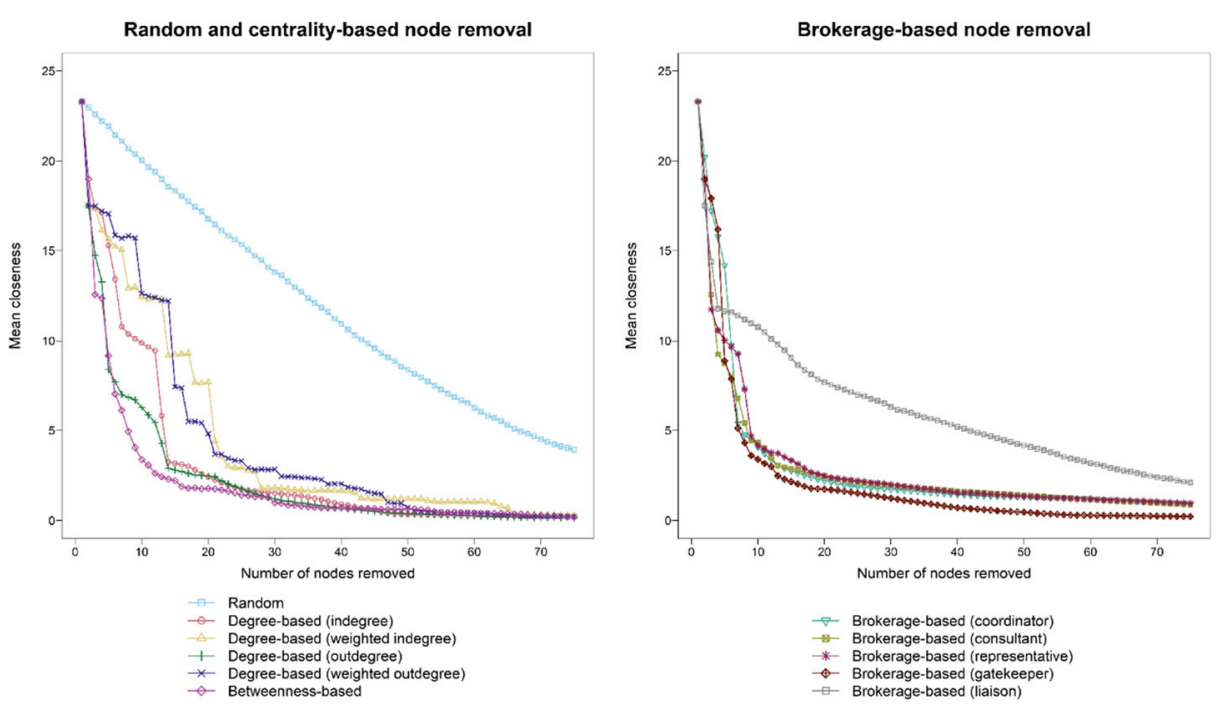

Fig. 8 Impact of different node removal strategies on the mean closeness of countries in the heroin network

geographical drivers - e.g. geographical proximity, levels of corruption, migration flows, size of the market - all strongly influence the formation of drug trafficking flows (Aziani, Berlusconi, and Giommoni 2019; Giommoni, Aziani, and Berlusconi 2017; Paoli, Greenfield, and Reuter 2009; Reuter 2014).

The results also confirm the notable role played by specific countries in international drug trafficking. For instance, the integral role played by Spain, Ecuador and Venezuela in cocaine trafficking should not come as a surprise considering their geographical and social proximity to producer countries in the Andes (Aziani, Berlusconi, and Giommoni 2019). Likewise, the study confirms the important role played by Pakistan and Bulgaria in the trafficking of heroin.
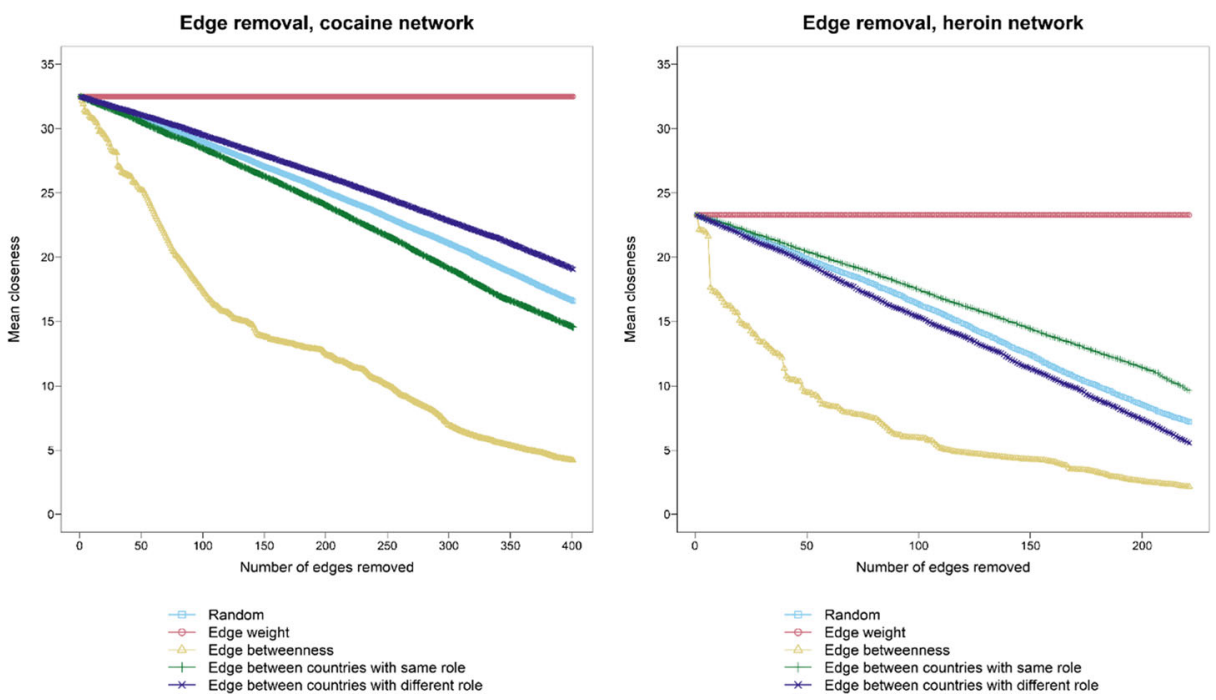

Fig. 9 Impact of different edge removal strategies on the mean closeness of countries in the cocaine (left) and heroin (right) networks 
Pakistan borders Afghanistan, which means that it is located at the very beginning of transnational supply chains of heroin. Bulgaria plays a crucial role in the Balkan route - the largest heroin trafficking route in the world - as it is one of the main entry points for Afghan opioids to Europe (UNODC 2015b).

However, some of our findings on the structure of the two networks have hitherto not been consolidated in extant literature on transnational drug trafficking. For instance, Spain had one of the highest degree and betweenness centrality scores, which signals its role as both an importer and exporter of cocaine and heroin. While its role in heroin trafficking is perhaps unexpected, this pattern may indicate the increased relevance of the Southern route (EMCDDA 2015, 2019; UNODC 2015a). Through the Southern route, heroin shipments from Iran and Pakistan are trafficked through African countries on their way to entering Europe, especially via Spain. For many years, the Balkan route has been the principal route through which heroin makes its way to Europe (UNODC 2015b). In recent years, instability within many African countries has presented new smuggling opportunities characterised by a lower risk of arrest for traffickers (Shaw and Tuesday 2019).

This study is the first to apply Gould and Fernandez's (1989) brokerage measures to international drug trafficking. While brokerage and betweenness centrality measures are highly correlated, the former provides a more precise indication of the specific roles that countries play in connecting different clusters. More specifically, brokerage measures reveal the nodes that connect producer, transit and consumer countries, which, in turn, make it possible for drug shipments to move along the transnational supply chain. For instance, the Netherlands often perform a representative role, along with playing a crucial role in connecting trafficking countries with consumer countries.

These results offer suggestions for developing targeted interventions aimed towards disrupting cocaine and heroin international trafficking. The study has shown that concentrating interdiction resources within the ten countries identified in this research as being integral to the cocaine trafficking network may prove to be more effective than the non-coordinated enforcement of cocaine flows within fifty countries. Similar indications emerge from the simulations conducted in relation to the heroin trafficking network. Enforcement strategies that focused on as few as three countries, which were selected according to their betweenness centrality, produced better results than the non-coordinated allocation of resources across thirty countries. Similarly, strategies that target drug routes, rather than countries, also showed some differences with respect to strategic and non-strategic interventions. Targeted interventions that were either driven by edge betweenness or focusing on the connections between countries in either different or similar clusters were found to be systematically more effective than random interventions, when at least twenty edges were targeted. Hence, while coordinating countermeasures at an international level is anything but straightforward, the improvements in terms of efficiency alone could be hugely substantial.

Given that countries have multiple connections in trafficking networks, targeting a limited number of countries is likely to reduce network connectivity more quickly than concentrating interdiction efforts on specific connections between countries. In fact, our analysis appears to suggest that targeting nodes is, from a network perspective, altogether more efficient. However, in practice, targeting specific connections - especially along land and air routes - may simply be easier for law enforcement agencies.

The aim of our simulations is to provide a support tool for drug interdiction, rather than putting forward a one-size-fits-all solution. Counter-drug strategies should thus be adjusted 
according to the number of countries or drug routes that law enforcement agencies can and want to focus their attention on, as well as the type of drugs. If the amount of allocated resources is limited, then the results from our simulations suggest that law enforcement authorities should base their interventions on countries with high betweenness scores or on those that play a coordinator or gatekeeper role. Conversely, if drug law enforcement authorities have a greater available budget - or face more difficulties in effectively coordinating between each other-, then degree-based interventions are also effective for disrupting international drug trafficking.

The results of our analysis could also be used to identify the set of countries that would cause the maximum amount of disruption within the two networks. Although cocaine and heroin are produced in different geographical areas, and are often trafficked by distinct criminal groups via different routes, this study identifies the points at which cocaine and heroin networks overlap. For instance, Spain emerges as the country where the allocation of proper resources could cause the greatest amount of disruption to both cocaine and heroin trafficking. Similarly, if we were to focus on only a single connection, then targeting drug flows between Portugal and Spain would likely have a disruptive effect on both cocaine and heroin cross-border trafficking. Indeed, the connection between the two countries was in the top ten for edge betweenness within both networks.

Transnational drug trafficking operates as a complex ecosystem. What happens, or does not happen, in one country can influence the entire trafficking network. For instance, the extent of cocaine or heroin trafficking in Ireland may have more to do with interventions in other key trafficking countries than it does with enforcement of the Irish borders. This predicate especially applies to countries within regional communities (e.g. European Union), where internal borders are minimal in order to facilitate trade between member states. Hence, even if Irish drug law enforcement were to heavily invest in counter-drug interdiction efforts, this would have little impact if the trafficking of cocaine and heroin continued to flow easily via Spain and other key countries within the EU. Conversely, countries like Ireland may achieve better results vis-à-vis disrupting trafficking flows by joining or financing interdiction activities in countries that play a key role in the cocaine and heroin networks.

Finally, it is worthwhile to discuss the main limitation of our simulations, i.e. the fact that they do not consider the fact that traffickers adapt to interdiction activities. For instance, drug traffickers can respond to law enforcement interventions by shifting to alternative routes, a phenomenon which is known as the 'balloon effect', or by resorting to alternative modes of transportation and/or hiding techniques (Friesendorf 2005; Guerette 2009; Magliocca et al. 2019; Reuter 2014; Toth and Mitchell 2018). Future research should thus seek to include a dynamic component within their simulations, in order to account for how trafficking activities can be displaced as a consequence of law enforcement interventions. Research in this area has hitherto been particularly scarce, in part because this kind of studies requires greater information about both traffickers' decision-making and the intensity of the interdiction.

\section{Conclusions}

The national and international drug control agenda is marked by a sharp misalliance, which pertains to the fact that the enforcement of illicit drugs receives the majority of 
the available funding, while the majority of drug control research focuses on treatment and interventions (Caulkins 2017). Moreover, research on drug treatment and prevention is far more voluminous and, generally, of a better scientific standard than research on drug enforcement (Caulkins 2017; Reuter 2017). These studies continuously develop new interventions aimed at determining what works best, for whom, and under which circumstances (Fischer et al. 2015; Stockings et al. 2016; Wu, Zhu, and Swartz 2016). In comparison, this kind of refined analysis is almost completely absent in the drug law enforcement literature (Reuter 2014).

This study provides a tool through which to help drug law enforcement agencies become more effective in their attempts to dismantle international drug trafficking. This study does not question the validity of supply-side policies per se. Rather, it provides empirical evidence about the vulnerability of cocaine and heroin international trafficking networks, in conjunction with identifying where drug law enforcement agencies interventions are most likely to cause the maximum amount of disruption. More importantly, the study demonstrates that empirically-driven strategies can be twice as effective as non-strategic and non-coordinated interventions, while, simultaneously, using half of the resources. Consequently, this research does not simply indicate strategic interventions, but can also help to reduce costs, and, in turn, improve the overall cost-effectiveness of interdiction interventions.

The corollary of this study, and of a more active drug law enforcement research agenda generally, is that it can free up funding while, simultaneously, reducing the burden of countering strategies for the involved populations. Simply put, drug law enforcement interventions can achieve more with less, if they are informed by empirical evidence. Hence, the additional funding that would be made available as a consequence of designing more costeffective interventions could be reinvested in other under-resourced areas, such as drug enforcement research or treatment and prevention interventions. Research into drug law enforcement can thus be beneficial for the entire drug policy agenda.

Acknowledgements This article is dedicated to Professor Carlo Morselli. Carlo was unlike any other who worked in the field of criminal networks. This article would not exist without his prior work on networks and crime. The authors would like to thank Brenda Bastos Campos (University of Surrey) for her help with managing and cleaning the UNODC data on individual drug seizures. We also would like to thank the two anonymous reviewers for their constructive comments.

Author Contributions All authors contributed to the study conception and design. Material preparation, data collection, and analysis were performed by Luca Giommoni, Giulia Berlusconi, and Alberto Aziani. The first draft of the manuscript was written by Luca Giommoni and all authors commented on previous versions of the manuscript. All authors read and approved the final manuscript.

Funding This work was supported by the Economic and Social Research Council under Grant ES/S008853/1.

Data Availability The data that support the findings of this study are available on the UNODC website at https://dataunodc.un.org/ids.

\section{Compliance with Ethical Standards}

Conflict of Interest The authors declare that they have no conflict of interest. 
Interdicting International Drug Trafficking: a Network Approach for...

565

Appendix 1. Distribution of Cocaine (Top) and Heroin (Bottom) Seizure Cases by Importing Country (2011-2016)

年)

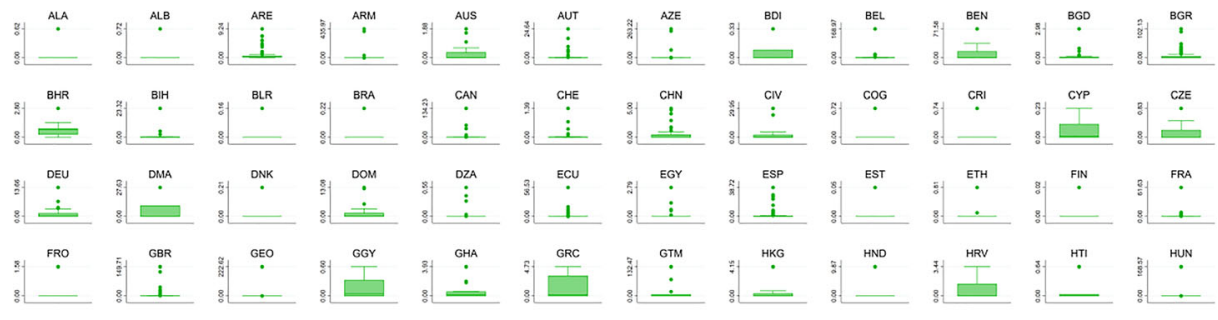

约兽

:

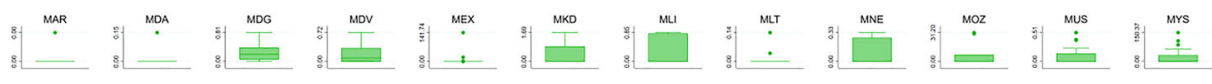

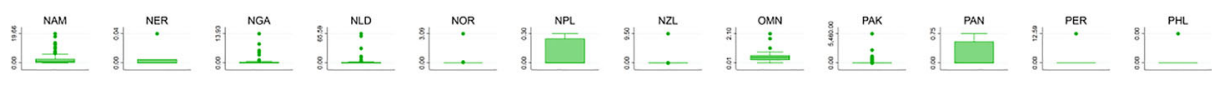

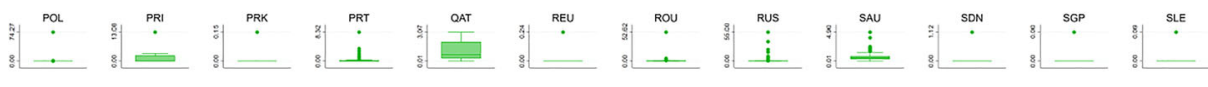

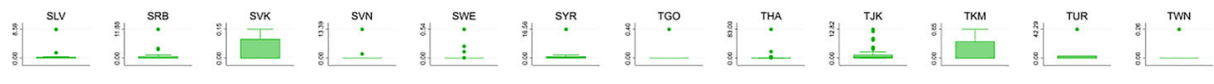

:

Springer 


\section{Appendix 2. Identification of Drug Connections Among Countries}

We can represent the trafficking network of drug $d$ in year $t$ by $N_{d, t}=\left(I_{d, t}, F_{d, t}\right)$, such that $\left\{i_{d, t}\right.$, $\left.{ }_{1}, i_{d, t, 2}, \ldots, i_{d, t, n}\right\}$ are the nodes, and $F_{d, t}=\{(j, k)\}$ are the weighted edges. The structure of $F_{d, t}$ was estimated based on information retrieved from the UNODC IDS dataset, as done in previous studies (e.g. Berlusconi, Aziani, and Giommoni 2017; Boivin 2013; Giommoni, Aziani, and Berlusconi 2017).

First, opium poppy derivatives $(29,559$ seizures $)$ were transformed to heroin-equivalent quantities according to conversion rates retrieved from the literature (Sanzharovskaya et al. 2013; UNODC 2019b). Similarly, quantities of coca derivatives (237,000 seizures) were converted to cocaine (UNODC 2010).

Second, we matched importing $\left(i_{d, t, j}\right)$ and exporting $\left(i_{d, t, k}\right)$ countries exploiting information on countries of production, departure, and destination of the seized drug loads, whenever available. After several checks (e.g. that $i_{d, t, j}$ is not equal to $i_{d, t, k}$ ), we were left with 13,021 seizure cases that provided information on edges in the cocaine trafficking network and 8052 seizure cases with information on edges in the heroin network. As certain seizure cases provided information on multiple connections, records of seizures of coca derivatives helped us identify 19,155 connections, while the connections emerging from the records of seizures of opium were 11,652 .

\section{Appendix 3. Consumption and Purity Adjusted Seizures}

The study combined a demand- and a supply-side approach to the estimate of the size of the national markets for illicit drugs $\left(M_{d, t, i}\right)$. The size of a national market was given by the sum of total consumption, $C_{d, t, i}^{p \_a d j}$ — expressed in pure quantity of consumed drug — and purity-adjusted seizures, $S_{d, t, i}^{p_{-} a d j}$. Annual estimates were produced for the years $(t)$ 2011-2016:

$$
M_{d, t, i}=C_{d, t, i}^{p-a d j}+S_{d, t, i}^{p-a d j}
$$

The consumption was given by the product of the prevalence of consumption in the 15-64 population $\left(p r_{d, t, i}\right)$ multiplied by the 15-64 population $\left(P o p_{t, i}\right)$, and by the estimated consumption per user at the global level $\left(\mathrm{c}_{d, t}\right)$ :

$$
C_{d, t, i}^{p_{-a d j}}=p r_{d, t, i} \cdot \operatorname{Pop}_{d, t, i} \cdot c_{d, t}
$$

The UNODC (2019a) provides time-series data on the prevalence of use of cocaine and heroin. Missing years were imputed through linear interpolation and extrapolation; whenever data for a country were missing for the entire 2011-2016 period, regional values were used to impute missing values. Population data were retrieved from the UNDESA (2019). Having estimates on prevalence and population size, it was possible to obtain the number of consumers per 
country. Data on consumption of drug per user are currently unavailable for most of the countries of the world. Therefore, the estimate of the consumption per user was obtained by adopting a supply-side approach. In particular, the estimates of the global productions of opium poppy and coca leaves gathered from the UNODC (2019b) were converted in equivalent masses of pure cocaine and heroin by adopting the conversion rates provided by the UNODC (2010). The total masses of available cocaine and heroin were then divided by the overall number of consumers, which was obtained by multiplying the prevalence of use by the population size in each country, and then summing the national estimates. This gave us an average consumption per user, which does not vary neither across countries nor by user typei.e. light and heavy users. The estimate of the annual average consumption of cocaine per user ranges between $4.7 \mathrm{~g}$ of perfectly pure cocaine in 2013 and 7.8 pure grams in 2016 . The annual consumption of heroin per user is between 3.6 pure grams in 2012 and 6.0 pure grams in 2014. Data on the global production of cocaine and heroin came from the UNODC (2019a).

To obtain purity-adjusted seizures, the registered volume of seizures $S_{d, i}$ was multiplied by the typical purity $p u_{d, i}$ of drug at the wholesale level in the country:

$$
S_{d, t, i}^{p_{-a d j}}=S_{d, t, i} \cdot p u_{d, t, i}
$$

Both data on total seizures and typical purity were retrieved from the UNODC (2019a). Missing observations on the purity level were estimated through linear interpolation and extrapolation. When no data on purity were available, regional and macro-regional averages were used to impute missing data.

\section{Appendix 4. Algebra Behind Import and Export Flows}

Except for producing countries, in year $t$, each country $i$ belonging to the global trafficking network of the drug $d$ imports from $K$ different countries a quantity of drug apt to satisfy its own internal demand-i.e. consumption $(C)$ and seizures $(S)$. The actual flow of drug entering the $i$ country is larger because of drug loads $(E)$ that are transiting through the country to reach other markets $(l)$. All these flows are bilateral so that exports from a given country are mirrored by imports from all other countries, and vice versa. As discussed in Appendix 2, it is possible to estimate consumption $(\dot{C})$ and seizures $(\dot{S})$ separately. Therefore, by solving a system of equations describing the relationship between internal demand and international flows for all the countries that are part of the trafficking network, it is possible to estimate the size of incoming and outgoing flows of drug:

$$
\left\{\begin{array}{c}
\sum_{k=1}^{K} I_{d, t, i \leftarrow k}=\left(\dot{C}_{d, t, i}+\dot{S}_{d, t, i}\right)+\sum_{l=1}^{L} E_{d, t, i \rightarrow l} \\
\sum_{l=1}^{L} E_{d, t, i \rightarrow l}=\sum_{l=1}^{L} I_{d, t, l \leftarrow i}
\end{array}\right.
$$


Appendix 5. Share of Imports of Cocaine (Top) and Heroin (Bottom) Which Are Seized, Consumed, and Exported by Importing Country (Average 2011-2016)

IER




SELA

Open Access This article is licensed under a Creative Commons Attribution 4.0 International License, which permits use, sharing, adaptation, distribution and reproduction in any medium or format, as long as you give appropriate credit to the original author(s) and the source, provide a link to the Creative Commons licence, and indicate if changes were made. The images or other third party material in this article are included in the article's Creative Commons licence, unless indicated otherwise in a credit line to the material. If material is not included in the article's Creative Commons licence and your intended use is not permitted by statutory regulation or exceeds the permitted use, you will need to obtain permission directly from the copyright holder. To view a copy of this licence, visit http://creativecommons.org/licenses/by/4.0/.

\section{References}

Angrist, J. D., \& Kugler, A. D. (2008). Rural windfall or a new resource curse? Coca, income, and civil conflict in Colombia. The Review of Economics and Statistics, 90(2), 191-215. https://doi.org/10.1162/rest.90.2.191.

Aziani, A. (2018). Illicit financial flows: An innovative approach to estimation. In International and Comparative Criminology. New York: Springer International Publishing.

Aziani, A., Berlusconi, G., \& Giommoni, L. (2019). A quantitative application of enterprise and social embeddedness theories to the transnational trafficking of cocaine in Europe. In Deviant Behavior online first (pp. 1-23).

Babor, T. F., Caulkins, J. P., Edwards, G., Fischer, B., Foxcroft, D. R., Humphreys, K., Obot, I. S., Rehm, J., \& Reuter, P. H. (2010). Drug policy and the public good. Oxford: Oxford University Press.

Balbirnie, E., Davies, M., Disley, E., Monsalve, C. G., Hartka, S., Hoorens, S., Kruithof, K., Sacher, M., \& Taylor, J. (2016). Mid-term assessment of the EU drugs strategy 2013-2020 and final evaluation of the action plan on drugs 2013-2016. Brussels: European Commission https://www.rand.org/pubs/research_ reports/RR1823.html.

Berlusconi, G., Aziani, A., \& Giommoni, L. (2017). The determinants of heroin flows in Europe: A latent space approach. Social Networks, 51, 104-117. 
Boivin, R. (2013). Drug trafficking networks in the world economy. In C. Morselli (Ed.), Crime and networks (pp. 182-194). New York: Routledge.

Boivin, R. (2014a). Macrosocial network analysis: The case of transnational drug trafficking. In A. J. Masys (Ed.), Networks and network analysis for defence and security (pp. 49-61). New York: Springer.

Boivin, R. (2014b). Risks, prices, and positions: A social network analysis of illegal drug trafficking in the worldeconomy. The International Journal on Drug Policy, 25(2), 235-243.

Bright, D., Greenhill, C., Britz, T., Ritter, A., \& Morselli, C. (2017). Criminal network vulnerabilities and adaptations. Global Crime, 18(4), 424-441. https://doi.org/10.1080/17440572.2017.1377614.

Butts, Carter T. 2015. Network: Classes for Relational Data (version 1.13.01). R package. https://CRAN.Rproject.org/package=network.

Butts, Carter T. 2016. Sna: Tools for Social Network Analysis (version 2.4). R package. http://CRAN.R-project. org $/$ package $=$ sna.

Caulkins, J. P. (2015). After the grand fracture: Scenarios for the collapse of the international drug control regime. Journal of Drug Policy Analysis, 2015(2), 8. https://doi.org/10.1515/jdpa-2015-0008.

Caulkins, J. P. (2017). Improving research on drug law enforcement. International Journal of Drug Policy, 41(March), 158-159. https://doi.org/10.1016/j.drugpo.2017.01.002.

Caulkins, J. P., \& Reuter, P. (2016). Dealing more effectively and humanely with illegal drugs. Crime and Justice, 46(1), 95-158. https://doi.org/10.1086/688458.

Caulkins, J. P., Crawford, G., \& Reuter, P. (1993). Simulation of adaptive response: A model of drug interdiction. Mathematical and Computer Modelling, 17(2), 37-52. https://doi.org/10.1016/0895-7177(93 )90238-T.

Chandra, S., \& Joba, J. (2015). Transnational cocaine and heroin flow networks in Western Europe: A comparison. International Journal of Drug Policy, 26(8), 772-780.

Chandra, S., Barkell, M., \& Steffen, K. (2011). Inferring cocaine flows across Europe: Evidence from price data. Journal of Drug Policy Analysis, 4(1), 1-18.

Chandra, S., Peters, S., \& Zimmer, N. (2014). How powdered cocaine flows across the United States evidence from open-source price data. Journal of Drug Issues, 44(4), 344-361.

Collins, J. (Ed.). (2014). Ending the drug wars. London: LSE IDEAS http://www.1se.ac. uk/ideas/Assets/Documents/reports/LSE-IDEAS-Ending-the-Drug-Wars.pdf.

Council of the European Union. (2012). European Union Drugs Strategy 2013-2020. Luxembourg: Publications Office of the European Union http://bookshop.europa.eu/en/european-union-drugs-strategy-2013-2020pbQC3213067/.

Crane, B. D., Rivolo, R. A., \& Comfort, G. C. (1997). An empirical examination of counterdrug interdiction program effectiveness. Alexandria: Institute for Defense Analysis.

Dugato, M., \& Aziani, A. (2020). Measuring (transnational) organized crime as an Indicator of global justice. Fudan Journal of the Humanities and Social Sciences, 13(2), 211-231. https://doi.org/10.1007/s40647-02000279-2.

Duijn, P. A. C., Kashirin, V., \& Sloot, P. M. A. (2014). The relative ineffectiveness of criminal network disruption. Scientific Reports, 4(1), 4238. https://doi.org/10.1038/srep04238.

Duxbury, S. W., \& Haynie, D. L. (2018). Building them up, breaking them down: Topology, vendor selection patterns, and a digital drug market's robustness to disruption. Social Networks, 52(January), 238-250. https://doi.org/10.1016/j.socnet.2017.09.002.

Duxbury, S. W., \& Haynie, D. L. (2019). Criminal network security: An agent-based approach to evaluating network resilience*. Criminology, 57(2), 314-342. https://doi.org/10.1111/1745-9125.12203.

EMCDDA. (2015). Opioid trafficking routes from Asia to Europe. Luxembourg: European Monitoring Centre for Drugs and Drug Addiction http://www.emcdda.europa.eu/system/files/publications/2747/att_239691_ EN Opioid\%20trafficking\%20routes POD2015.pdf.

EMCDDA. (2019). European drug report 2019: Trends and developments. Luxembourg: Publications Office of the European Union http:/www.emcdda.europa.eu/system/files/publications/11364/20191724_TDAT19001 ENN PDF.pdf.

Executive Office of the President of the United States. (2017). National Drug Control Budget: FY 2018 Funding Highlights. Washington D.C: Executive Office of the President of the United States https://www. whitehouse.gov/sites/whitehouse.gov/files/ondcp/Fact_Sheets/FY2018-Budget-Highlights.pdf\#targetText= The $\% 20$ President's\%20FY\%202018\%20Budget,and\%20the\%20District\%20of\%20Columbia.

Felbab-Brown, V. (2014). Improving supply-side policies: Smarter eradication, interdiction and alternative livelihoods-And the possibility of licensing. In J. Collins (Ed.), Ending the drug wars (pp. 41-48). London: LSE IDEAS http://www.lse.ac.uk/ideas/publications/reports/pdf/lse-ideas-drugs-report-final-web. pdf.

Fischer, B., Blanken, P., Da Silveira, D., Gallassi, A., Goldner, E. M., Rehm, J., Tyndall, M., \& Wood, E. (2015). Effectiveness of secondary prevention and treatment interventions for crack-cocaine abuse: A 
comprehensive narrative overview of English-language studies. International Journal of Drug Policy, 26(4), 352-363. https://doi.org/10.1016/j.drugpo.2015.01.002.

Freeman, L. C. (1979). Centrality in social networks: Conceptual clarification. Social Networks, 1(3), 223-258.

Friesendorf, C. (2005). Squeezing the balloon?: United States air interdiction and the restructuring of the south American drug industry in the 1990s. Crime, Law and Social Change, 44(1), 35-78. https://doi.org/10.1007 /s10611-006-9005-9.

Giommoni, L., Aziani, A., \& Berlusconi, G. (2017). How do illicit drugs move across countries? A network analysis of the heroin supply to Europe. Journal of Drug Issues, 47(2), 1.

Gould, R. V., \& Fernandez, R. M. (1989). Structures of mediation: A formal approach to brokerage in transaction networks. Sociological Methodology, 19, 89-126. https://doi.org/10.2307/270949.

Guerette, R. T. (2009). Analyzing crime displacement and diffusion. In 10. Problem-Oriented Guides for Police: Problem-Solving Tools Series. U.S. Department of Justice: Office of Community Oriented Policing Services https://ric-zai-inc.com/Publications/cops-p167-pub.pdf.

Kilmer, B., \& Hoorens, S. (2010). Better understanding efforts to reduce the supply of illicit drugs. Santa Monica: RAND Corporation http:/www.rand.org/pubs/research_briefs/RB9521.html.

Kilmer, B., Caulkins, J. P., Pacula, R. L., \& Reuter, P. H. (2011). Bringing perspective to illicit markets: Estimating the size of the U.S. marijuana market. Drug and Alcohol Dependence, 119(1-2), 153-160.

Kilmer, B., Caulkins, J. P., Midgette, G., Dahlkemper, L., MacCoun, R. J., \& Pacula, R. L. (2013). Before the grand opening. Measuring Washington State's marijuana market in the last year before legalized commercial sales. Santa Barbara: RAND Corporation http://www.rand.org/pubs/research_reports/RR466.html.

Kilmer, B., Reuter, P. H., \& Giommoni, L. (2015). What can be learned from cross-national comparisons of data on illegal drugs? Crime and Justice, 44(1), 227-296.

Kleiman, M. A. R. (1999). Against excess: Drug policy for results (Reprint ed.). New York: Basic Books.

Kleiman, M. A. R. (2011). Surgical strikes in the drug wars: Smarter policies for both sides of the border. Foreign Affairs, 90(5), 89-101.

Legleye, S., Lakhdar, C. B., \& Spilka, S. (2008). Two ways of estimating the euro value of the illicit market for cannabis in France. Drug and Alcohol Review, 27(5), 466-472.

MacCoun, R., \& Reuter, P. H. (2001). Drug war heresies: Learning from other, vices, times, \& places. New York: Cambridge University Press.

Magliocca, N. R., McSweeney, K., Sesnie, S. E., Tellman, E., Devine, J. A., Nielsen, E. A., Pearson, Z., \& Wrathall, D. J. (2019). Modeling cocaine traffickers and counterdrug interdiction forces as a complex adaptive system. Proceedings of the National Academy of Sciences, 116(16), 7784-7792. https://doi. org/10.1073/pnas.1812459116.

Malm, A., \& Bichler, G. (2011). Networks of collaborating criminals: Assessing the structural vulnerability of drug markets. Journal of Research in Crime and Delinquency, 48(2), 2011. https://doi.org/10.1177 $/ 0022427810391535$.

Manski, C. F., Pepper, J. V., \& Petrie, C. V. (2001). Informing America's policy on illegal drugs: What we don't know keeps hurting us. National Research Country: Washington D.C http://www.nap.edu/openbook. php?isbn=0309072735.

Marshall, E. (1988). Flying blind in the war on drugs. Science, 240(4859), 1605-1607.

Mejía, D., \& Restrepo, P. (2016). The economics of the war on illegal drug production and trafficking. Journal of Economic Behavior \& Organization, 126, 255-275.

Meylakhs, P. (2017). The current state of the world heroin markets. In E. U. Savona, M. A. R. Kleiman, \& F. Calderoni (Eds.), Dual markets: Comparative approaches to regulation (pp. 21-35). Cham: Springer International Publishing. https://doi.org/10.1007/978-3-319-65361-7_2.

Morselli, C., \& Petit, K. (2007). Law-enforcement disruption of a drug importation network. Global Crime, 8(2), 109-130. https://doi.org/10.1080/17440570701362208.

Opsahl, T., Agneessens, F., \& Skvoretz, J. (2010). Node centrality in weighted networks: Generalizing degree and shortest paths. Social Networks, 32(3), 245-251. https://doi.org/10.1016/j.socnet.2010.03.006.

Paoli, L., Greenfield, V. A., \& Reuter, P. H. (2009). The world heroin market: Can supply be cut? New York: Oxford University Press.

R Core Team. (2019). R: A Language and Environment for Statistical Computing (version 3.6.1. Vienna: R Foundation for Statistical Computing https://www.R-project.org.

Reuter, P. H. (2014). The mobility of drug trafficking. In J. Collins (Ed.), Ending the drug wars. Report of the LSE Expert Group on the economics of drug policy (pp. 33-40). London: The London School of Economics and Political Science.

Reuter, P. H. (2017). Creating a drug law enforcement research agenda. International Journal of Drug Policy, 41, $160-161$.

Reuter, P. H., \& Greenfield, V. A. (2001). Measuring global drug markets. How good are the numbers and why should we care about them? World Economics, 2(4), 159-173. 
Reuter, P. H., Crawford, G., Cave, J., Murphy, P., Henry, D., Lisowski, W., \& Wainstein, E. S. (1988). Sealing the borders. The effects of increased military participation in drug interdiction. Santa Monica: RAND Drug Policy Research Center http://www.rand.org/pubs/reports/R3594.html.

Rigter, H. (2006). What drug policies cost. Drug policy spending in the Netherlands in 2003. Addiction, 101(3), 323-329.

Sanzharovskaya, M., Budankova, E., Fisenko, A., Kuzin, E., Ustyuzhanina, E., Chernyavskaya, G., \& Chernogoryuk, G. (2013). Bullous emphysema and severe COPD in acetylated opium users. European Respiratory Journal, 42(Suppl 57), 3298.

Shaw, M., \& Tuesday, R. (2019). Organized crime and criminal networks in Africa. In Oxford Research Encyclopedia of Politics.

Stockings, E., Hall, W. D., Lynskey, M., Morley, K. I., Reavley, N., Strang, J., Patton, G., \& Degenhardt, L. (2016). Prevention, early intervention, harm reduction, and treatment of substance use in young people. The Lancet Psychiatry, 3(3), 280-296. https://doi.org/10.1016/S2215-0366(16)00002-X.

Toth, A. G., \& Mitchell, O. (2018). A qualitative examination of the effects of international counter-drug interdictions. The International Journal on Drug Policy, 55, 70-76.

UNDESA. (2019). World population prospects 2019. In Drugs Monitoring Platform (Vol. 2019) https://population.un.org/wpp/.

UNODC. (2010). Methodology-World drug report 2010. Vienna: UNODC https://www.unodc. org/documents/data-and-analysis/WDR2010/WDR2010methodology.pdf.

UNODC. (2015a). Afghanistan opiate trafficking through the southern route. Vienna: UNODC https://www. unodc.org/documents/data-and-analysis/Studies/Afghan_opiate_trafficking_southern_route_web.pdf.

UNODC. (2015b). Drug money: The illicit proceeds of opiates trafficked on the Balkān route. Wien: United Nations Office on Drug and Crime.

UNODC. (2019a). World drug report 2019. Vienna: United Nations Office on Drugs and Crime https://wdr. unodc.org/wdr2019/.

UNODC. (2019b). World drug report 2019 methodology report. Vienna: United Nations Office on Drugs and Crime https://wdr.unodc.org/wdr2019/prelaunch/WDR-2019-Methodology-FINAL.pdf.

Veillette, C. (2005). Plan Colombia: A progress report. In Congressional Research Service http://www. securityassistance.org/sites/default/files/050217crs.pdf.

Wasserman, S., \& Faust, K. (1994). Social Network Analysis: Methods and Applications (1st ed.). Cambridge ; New York: Cambridge University Press.

Wilkins, C., Bhatta, K., \& Casswell, S. (2002). A 'demand side' estimate of the dollar value of the cannabis black market in New Zealand. Drug and Alcohol Review, 21(2), 145-151.

Wood, G. (2017). The structure and vulnerability of a drug trafficking collaboration network. Social Networks, 48(January), 1-9. https://doi.org/10.1016/j.socnet.2016.07.001.

Wu, L.-T., Zhu, H., \& Swartz, M. S. (2016). Treatment utilization among persons with opioid use disorder in the United States. Drug and Alcohol Dependence, 169(December), 117-127. https://doi.org/10.1016/j. drugalcdep.2016.10.015.

Publisher's Note Springer Nature remains neutral with regard to jurisdictional claims in published maps and institutional affiliations. 